\title{
Inhibiting Effect of Tetra-n-Butylammonium Iodide on the Corrosion of Mild Steel in Acidic Medium
}

\author{
Monika, ${ }^{*}$ and W.A. Siddique \\ Department of Applied Sciences and Humanities, Faculty of Engineering and Technology, \\ Jamia Millia Islamia, New Delhi-110025, INDIA
}

Received 21 January 2007; accepted 20 July 2007

\begin{abstract}
The inhibition effect of tetra-N-butylammonium iodide (TBAI) on mild steel in $1 \mathrm{~N}$ $\mathrm{H}_{2} \mathrm{SO}_{4}$ has been studied by using weight loss, electrochemical polarization, Fourier Transform Infrared (FTIR) and scanning electron microscopic (SEM) techniques. It has been concluded that the percentage inhibition increases with increasing the concentration of the inhibitor. The adsorption of TBAI on mild steel surface in $1 \mathrm{~N}$ $\mathrm{H}_{2} \mathrm{SO}_{4}$ obeys Langmuir adsorption isotherm; surface analysis and IR studies are also carried out to establish the mechanism of corrosion inhibition.
\end{abstract}

Keywords: corrosion, mild steel, $\mathrm{H}_{2} \mathrm{SO}_{4}$, tetra-N-butylammonium iodide (TBAI).

\section{Introduction}

Corrosion is a destructive attack of metal by its environment. Inhibitors are generally used to protect materials against deterioration from corrosion. Many organic compounds containing oxygen, nitrogen and sulphur have been used as corrosion inhibitors for metal [1-10]. Amines are effective inhibitors for steel corrosion in acidic solution [11-13]. The present paper deals with the study of inhibiting action of TBAI on mild steel in acidic solution. The electrochemical behavior of mild steel in $\mathrm{H}_{2} \mathrm{SO}_{4}$ media in absence and presence of the inhibitor has been studied by galvanostatic polarization, IR and SEM method.

\section{Experimental}

The mild steel coupons of composition ( $C=0.10-0.20 \%, M n=0.40-0.50 \%$, $\mathrm{Si}=0.05 \%, \mathrm{~S}=0.025-0.030 \%, \mathrm{P}=0.30-0.80 \%$ and the rest being $\mathrm{Fe}$ ) and of size (i.e., $0.8 \times 0.8 \times 3.0 \mathrm{~cm}$ ) have been used for weight loss measurements. These coupons have been given mechanical polishing and then degreased before use.

\footnotetext{
*Corresponding author. E-mail address:jmi_bansal24@yahoo.com; weqar_ah@yahoo.com
} 
The inhibition efficiency for different concentrations of the inhibitor is calculated from weight loss values.

The electrodes are polished with emery papers and degreased. AR grade of $\mathrm{H}_{2} \mathrm{SO}_{4}$ is used for preparing solutions, as well as double distilled water. For accurate measurements of potential and current densities, galvanostatic polarization studies were carried out at different temperatures. A platinum foil and saturated calomel electrode are used as counter and reference electrodes, respectively. Polarization was carried out in $\mathrm{H}_{2} \mathrm{SO}_{4}$ in the absence and presence of the inhibitor at various concentrations and temperatures.

The Fourier Transform Infrared Spectroscopic analysis (FTIR) spectra of pure inhibitor as well as spectra of inhibitors adsorbed on silica gel are recorded by using a Perkin Elmer Infrared Spectroscope IR 137. The pure saturated solutions of additive are prepared in solvent, i.e., benzene, in which the compound is soluble. Now silica gel, which is dried in an oven to remove the moisture, is added in the additive. The dried solid pallet of the additive mixed in silica gel is used to record the FTIR spectra.

To know the surface morphology of mild steel, scanning electron microscopy technique using a LEO 435 V.P. Scanning Electron Microscope is used. The polished specimens have been examined by optical microscope to find out any surface defects, and we took those which have smooth surfaces. After this the specimens have been washed with double distilled water and dried in desiccators. These specimens are dipped in solutions of $10^{-1} \mathrm{M}$ and $10^{-7} \mathrm{M}$ concentration for the inhibitor in $1 \mathrm{~N}$ sulphuric acid for 24 hours at room temperature. These specimens are then washed with distilled water and dried in a desiccator. SEM photographs of these corroded specimens are recorded.

\section{Results and discussion}

Weight loss measurement

The corrosion inhibition efficiency of TBAI for corrosion of mild steel is calculated as follows

$$
\% \text { Efficiency }=\frac{w_{0}-w}{w_{0}} \times 100
$$

where $w_{0}$ and $w$ are the values of corrosion weight loss of steel without and with inhibitor, respectively. Table 1 gives the values of inhibition efficiencies obtained from weight loss study for various concentrations and temperatures. It has been observed that the inhibition efficiencies slightly change as the temperature increases from $298 \mathrm{~K}$ to $328 \mathrm{~K}$ for $10^{-1} \mathrm{M}$ concentration. The change in inhibition efficiencies is quite less for all concentrations viz. $10^{-1} \mathrm{M}, 10^{-3} \mathrm{M}$, $10^{-5} \mathrm{M}$ and $10^{-7} \mathrm{M}$ at $298 \mathrm{~K}$, while changes in inhibition efficiencies are stronger as the temperature increases from $308 \mathrm{~K}$ to $328 \mathrm{~K}$ for all concentrations. 
Table 1. Inhibition efficiency of tetra-N-butylammonium iodide (TBAI).

\begin{tabular}{cccc}
\hline Temperature & Solution/mol $\left(\mathrm{L}^{-1}\right)$ & Weight loss/gram & $\% \mathrm{I}$ \\
& & & \\
\hline $298 \mathrm{~K}$ & $1 \mathrm{~N} \mathrm{H}_{2} \mathrm{SO}_{4}$ & 0.0786 & - \\
& $10^{-7}$ & 0.0099 & 87.40 \\
& $10^{-5}$ & 0.0073 & 90.71 \\
& $10^{-3}$ & 0.0041 & 94.78 \\
$308 \mathrm{~K}$ & $10^{-1}$ & 0.0035 & 95.54 \\
& $1 \mathrm{~N} \mathrm{H}_{2} \mathrm{SO}_{4}$ & 0.1568 & - \\
& $10^{-7}$ & 0.0715 & 54.40 \\
& $10^{-5}$ & 0.0598 & 61.86 \\
$318 \mathrm{~K}$ & $10^{-3}$ & 0.0179 & 88.58 \\
& $10^{-1}$ & 0.0071 & 95.47 \\
& $1 \mathrm{~N} \mathrm{H}_{2} \mathrm{SO}_{4}$ & 0.5468 & - \\
& $10^{-7}$ & 0.3454 & 36.83 \\
& $10^{-5}$ & 0.2374 & 56.58 \\
& $10^{-3}$ & 0.1675 & 69.36 \\
& $10^{-1}$ & 0.0260 & 95.24 \\
& $1 \mathrm{~N} \mathrm{H}_{2} \mathrm{SO}_{4}$ & 1.1891 & - \\
& $10^{-7}$ & 0.8028 & 32.48 \\
& $10^{-5}$ & 0.6849 & 42.40 \\
& $10^{-3}$ & 0.2349 & 80.24 \\
& $10^{-1}$ & 0.0683 & 94.25 \\
\hline
\end{tabular}

\section{Polarization measurement}

Fig. 1 to 4 show the anodic and cathodic polarization curves (Tafel's plot) of mild steel in $1 \mathrm{~N} \mathrm{H}_{2} \mathrm{SO}_{4}$ solution with and without the addition of various concentration of TBAI at different temperatures, i.e., $298 \mathrm{~K}, 308 \mathrm{~K}, 318 \mathrm{~K}$ and $328 \mathrm{~K}$. Various electrochemical parameters are given in Table 2: corrosion current density $\left(\mathrm{I}_{\text {corr }}\right)$, corrosion potential $E_{\text {corr }}$, Tafel's values $b_{a}$ and $b_{c}$ for different concentrations. The corrosion current densities are calculated by intersection method, i.e., by extra plotting the tangents of anodic and cathodic curves and their intersection with corrosion potential. These curves explain the corrosion current densities decrease with increasing the concentration of the inhibitor. The percentage inhibition of each inhibitor at various concentrations in $1 \mathrm{~N} \mathrm{H}_{2} \mathrm{SO}_{4}$ is shown in Table 2 after being calculated from the expression

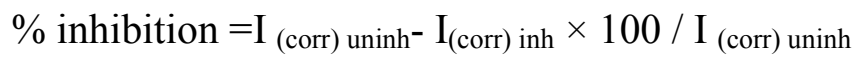

The percentage inhibition of TBAI on mild steel in $1 \mathrm{~N} \mathrm{H}_{2} \mathrm{SO}_{4}$ shows that the corrosion inhibition efficiency reaches about $95.2 \%$ with solution containing $10^{-1}$ $\mathrm{M}$ inhibitor concentration, whereas at low concentration $\left(10^{-7} \mathrm{M}\right)$ the percentage inhibition is about $87.41 \%$ at $298 \mathrm{~K}$, while at $328 \mathrm{~K}$ the corrosion inhibition efficiency reaches $94.8 \%$ with solution containing $10^{-1} \mathrm{M}$ inhibitor. On the other hand the percentage inhibition efficiency is about $33.93 \%$ containing solution $10^{-7} \mathrm{M}$ concentration. This effect could be attributed to the fact that the inhibition increases due to large alkyl chain group, which causes enough coverage on the 
metal surface. This way small area of electrode surface is left uncovered, which produces less corrosion on mild steel. The trend in the values of $b_{c}$ and $b_{a}$ suggests here that many inhibitor processes are participating in corrosion inhibition.

From the experimental method, it is concluded that the inhibitor effect is anodic at $298 \mathrm{~K}$ rather than cathodic, except for $10^{-1} \mathrm{M}$. At higher temperature the inhibitor TBAI is of the anodic type.

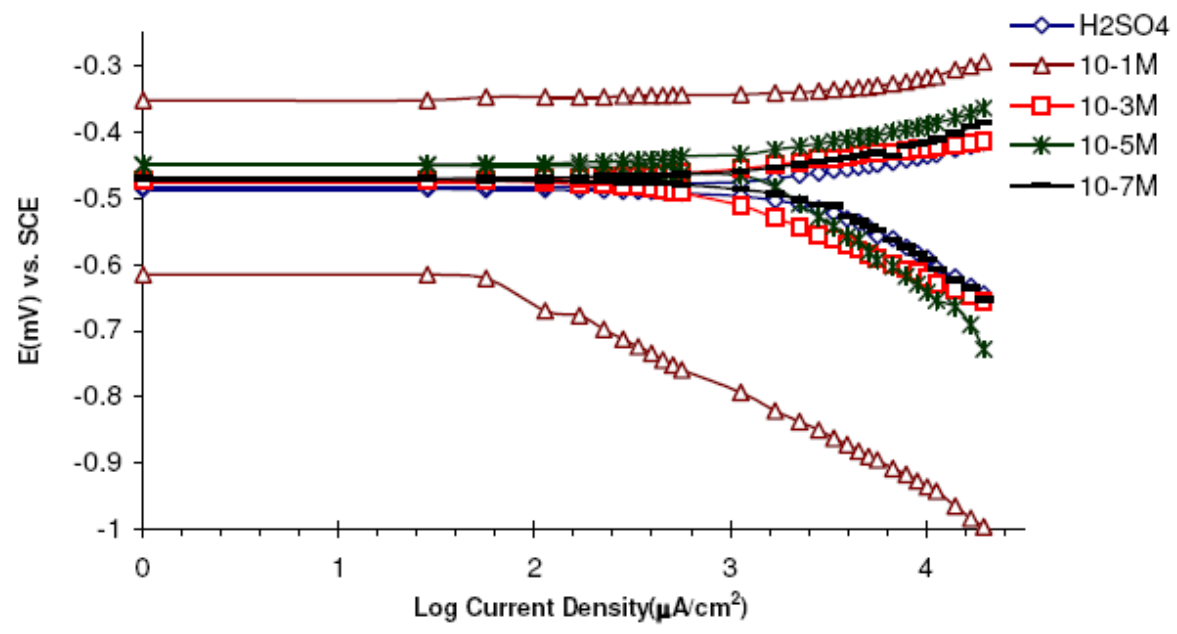

Figure 1. Galvanostatic polarization curves of mild steel in $1 \mathrm{~N} \mathrm{H}_{2} \mathrm{SO}_{4}$ solution in the presence of different concentrations of TBAI at $298 \mathrm{~K}$.

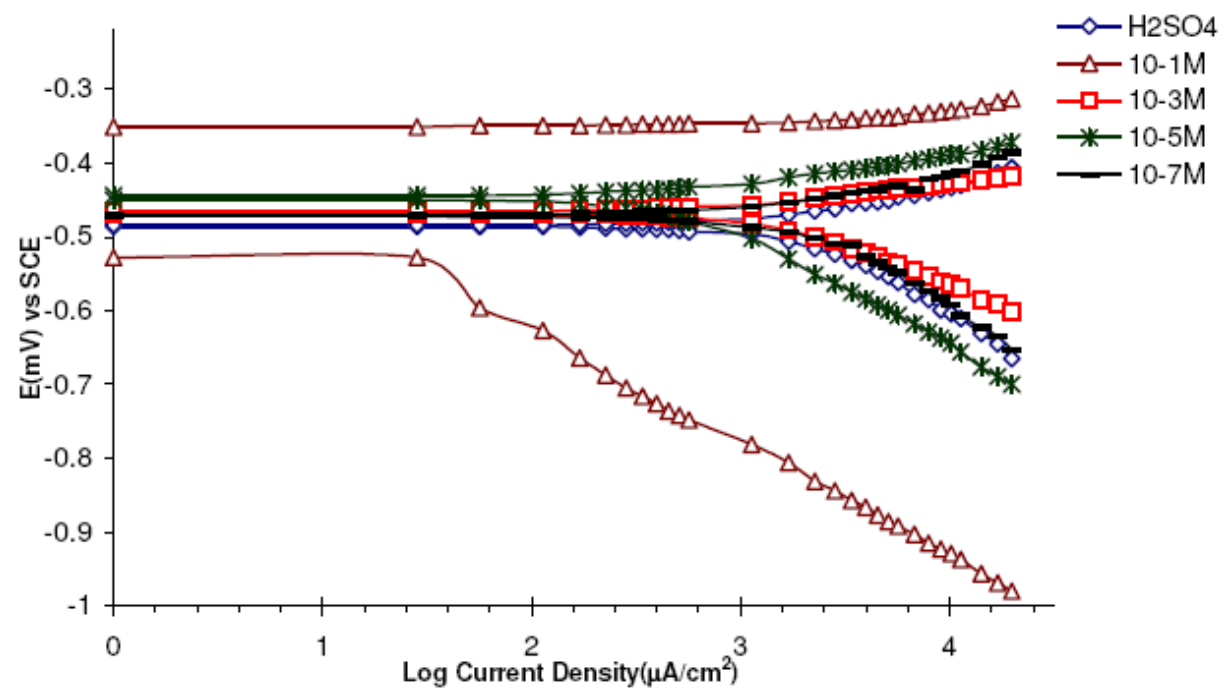

Figure 2. Galvanostatic polarization curves of mild steel in $1 \mathrm{~N} \mathrm{H}_{2} \mathrm{SO}_{4}$ solution in the presence of different concentrations of TBAI at $308 \mathrm{~K}$. 


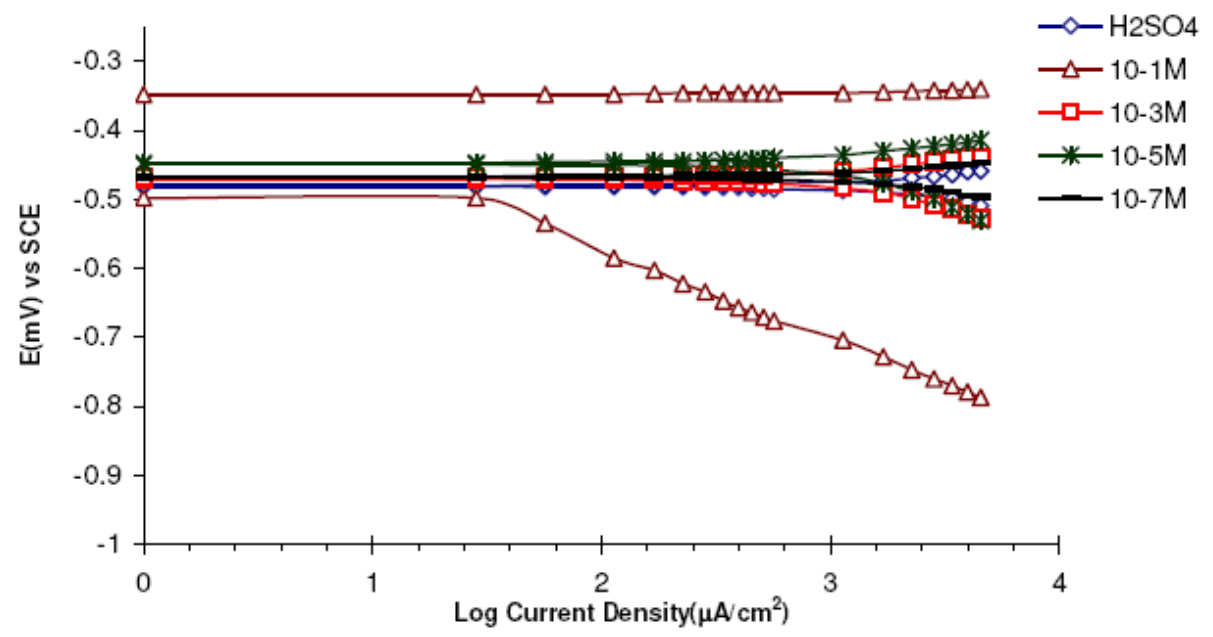

Figure 3. Galvanostatic polarization curves of mild steel in $1 \mathrm{~N} \mathrm{H}_{2} \mathrm{SO}_{4}$ solution in the presence of different concentrations of TBAI at $318 \mathrm{~K}$.

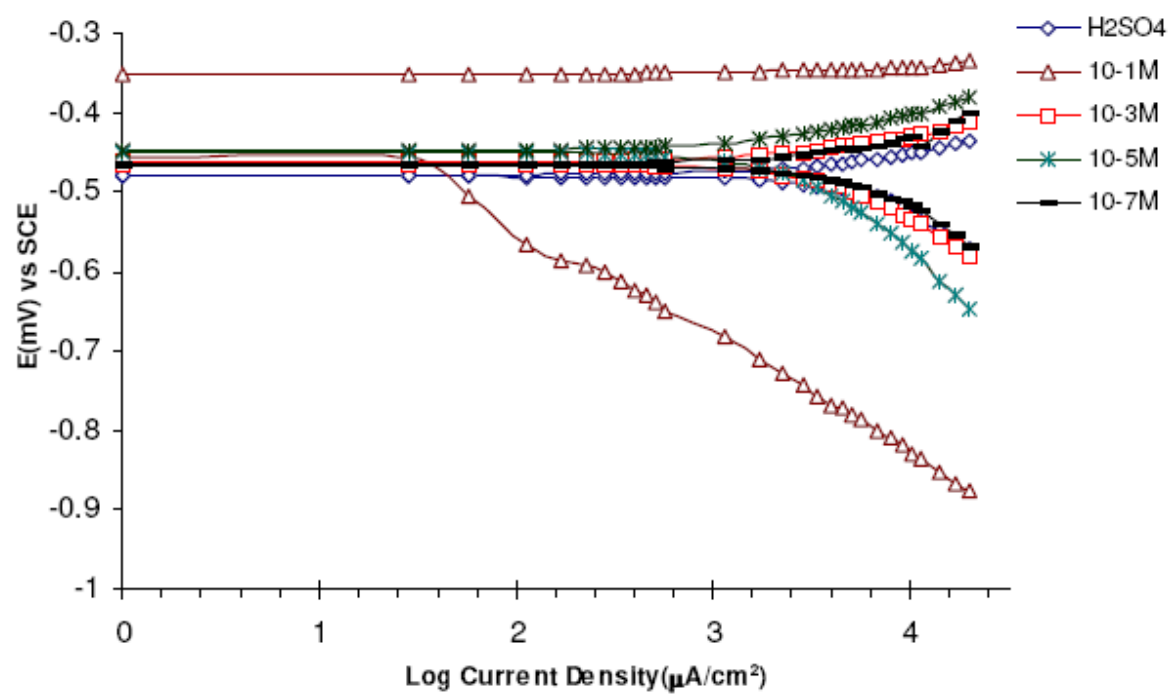

Figure 4. Galvanostatic polarization curves of mild steel in $1 \mathrm{~N} \mathrm{H}_{2} \mathrm{SO}_{4}$ solution in the presence of different concentrations of TBAI at $328 \mathrm{~K}$.

\section{Adsorption kinetics}

With high concentration of the inhibitor, a protective inhibitor layer formed on the mild steel surface, which reduces the chemical attack of metal. The surface coverage $\theta$ values have been obtained from electrochemical measurements for various concentrations. There are many adsorption isotherms to study the adsorption process. Here Langmuir adsorption isotherm is tested. Fig. 5 shows the plot of $\log \theta / 1-\theta$ vs. $\log C$ graph, a straight line with approximately unit slope. The value of heat of adsorption can be calculated from the formula

$$
\log \frac{\theta}{1-\theta}=\log A+\log C-\frac{Q_{a d s}}{2.3 R T}
$$

where $\mathrm{A}$ is Arrhenius constant, $\mathrm{C}$ is the inhibitor concentration and $\mathrm{Q}$ is heat of adsorption.

The value of heat of adsorption for TBAI is $4.50 \mathrm{kcal} / \mathrm{mol}$. 
Table 2. Corrosion parameters of mild steel in $1 \mathrm{~N} \mathrm{HNO}_{3}$ in the presence of tetra-Nbutylammonium iodide (TBAI) as additive.

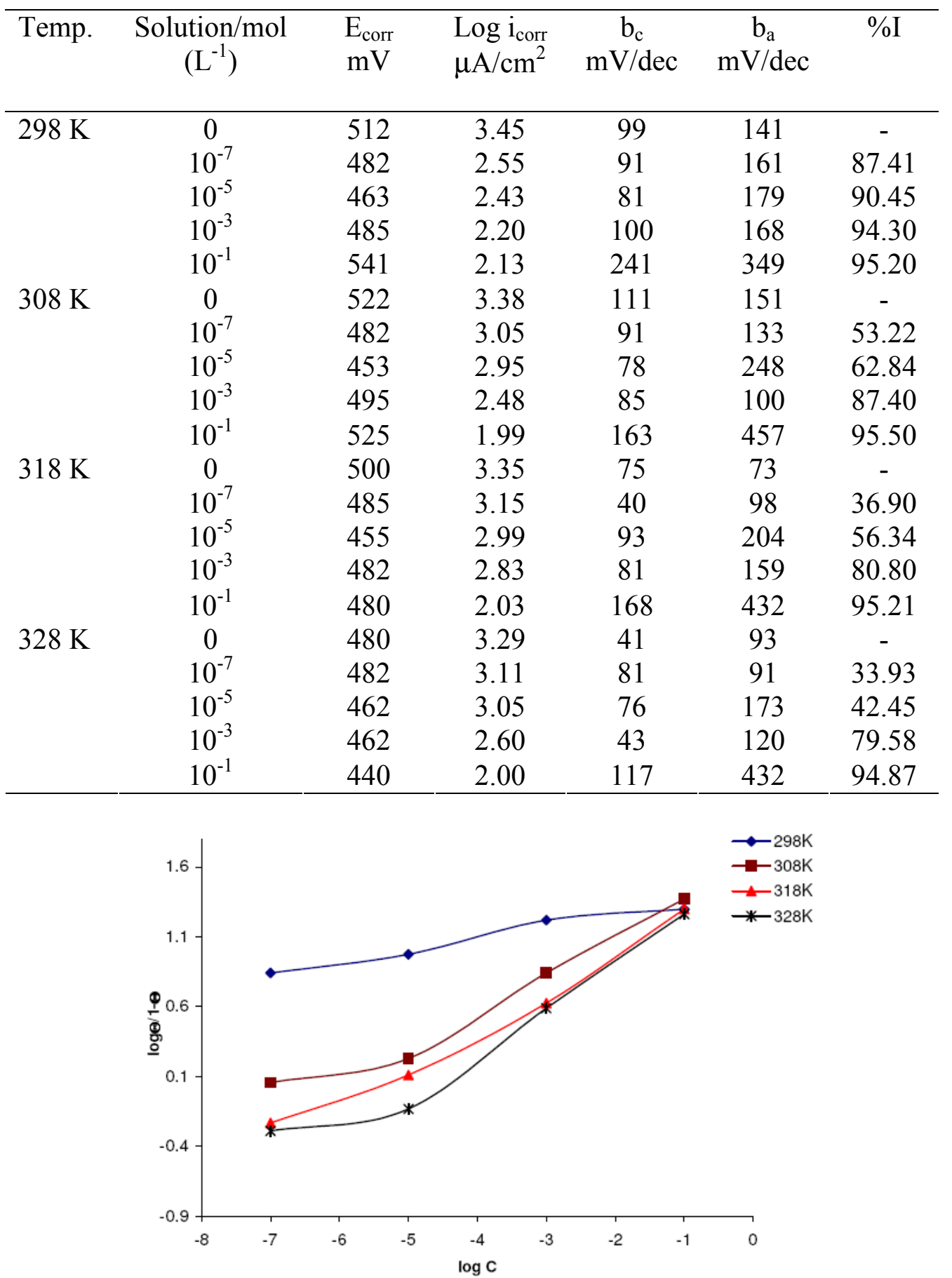

Figure 5. Variation of the surface coverage vs. concentration at different temperatures of TBAI.

To calculate the activation energy, the current densities are plotted against temperature in absence and presence of the inhibitor (Fig. 6). The value of activation energy can be found out by Arrhenius equation

$$
\frac{\partial \log I_{c o r r}}{\partial \mathrm{T}}=\frac{\mathrm{E}_{a}}{R T^{2}}
$$


where $E_{a}$ is the activation energy. The value of activation energy of TBAI is $64.31 \mathrm{Kcal} / \mathrm{mol}$.

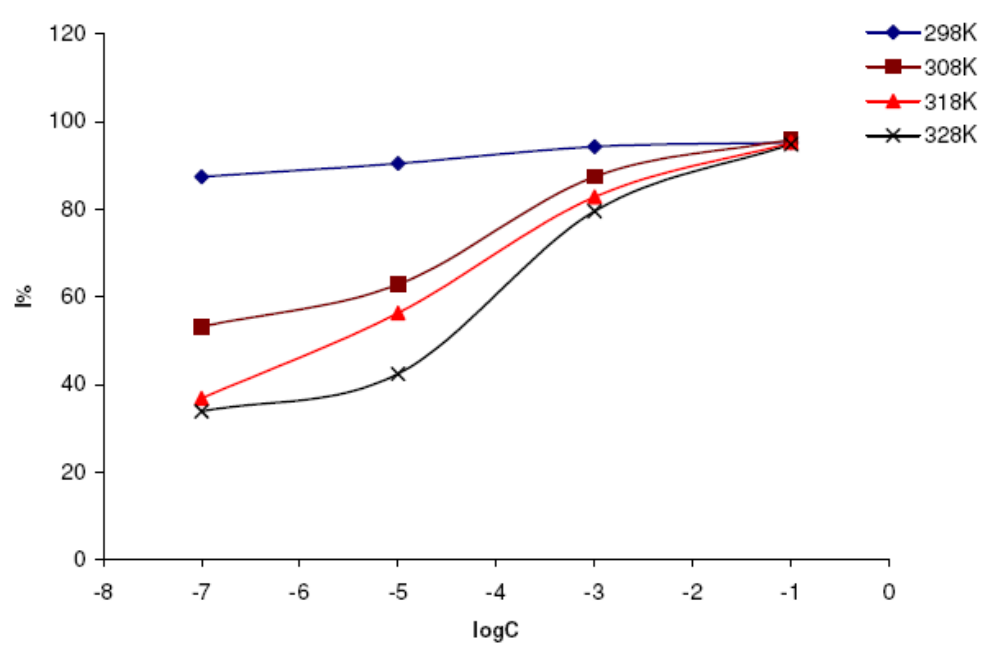

Figure 6. Inhibition efficiency vs. concentration of TBAI at different temperatures.

\section{FTIR study of the inhibitor}

To find out the types of bonding for organic molecules adsorbed on the surface of the solid, FTIR study has been conducted. Silica gel has been chosen because of large surface area of adsorption of organic molecules and yields a spectrum of moderate intensity. The various peaks in spectra of pure and silica gel adsorbed additives are shown in Fig. 7 and 8 and there vibrational modes are reported in Table 3. The spectra of TBAI indicate the disappearance of $\mathrm{N}-\mathrm{C}, \mathrm{N}-\mathrm{H},-\mathrm{CH}_{2}-$ and $\mathrm{N}-\mathrm{H}_{\text {wagg }}$ and merging of two peaks for $\mathrm{C}-\mathrm{H}_{\text {str }}$ bond into a single peak. From the above observation it can be concluded that the adsorption of this inhibitor over solid surface takes place through $\mathrm{N}-\mathrm{C}$ bond, $\mathrm{N}-\mathrm{H}$ bond and $\mathrm{N}-\mathrm{H}_{\text {wagg. }}$.

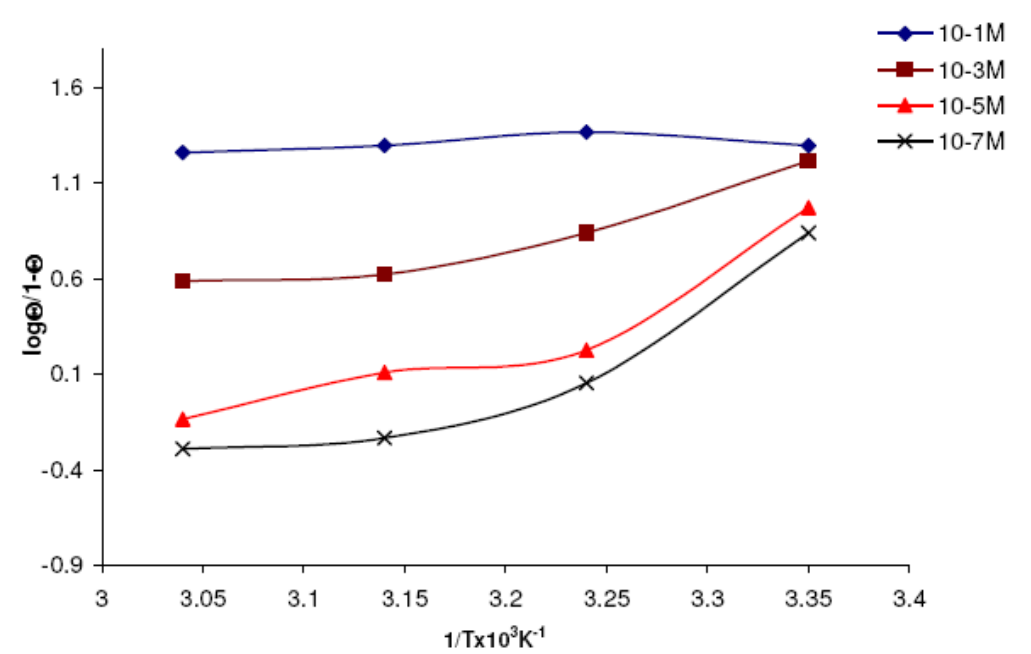

Figure 7. Variation of surface coverage vs. reciprocal of temperature at different concentrations of TBAI. 


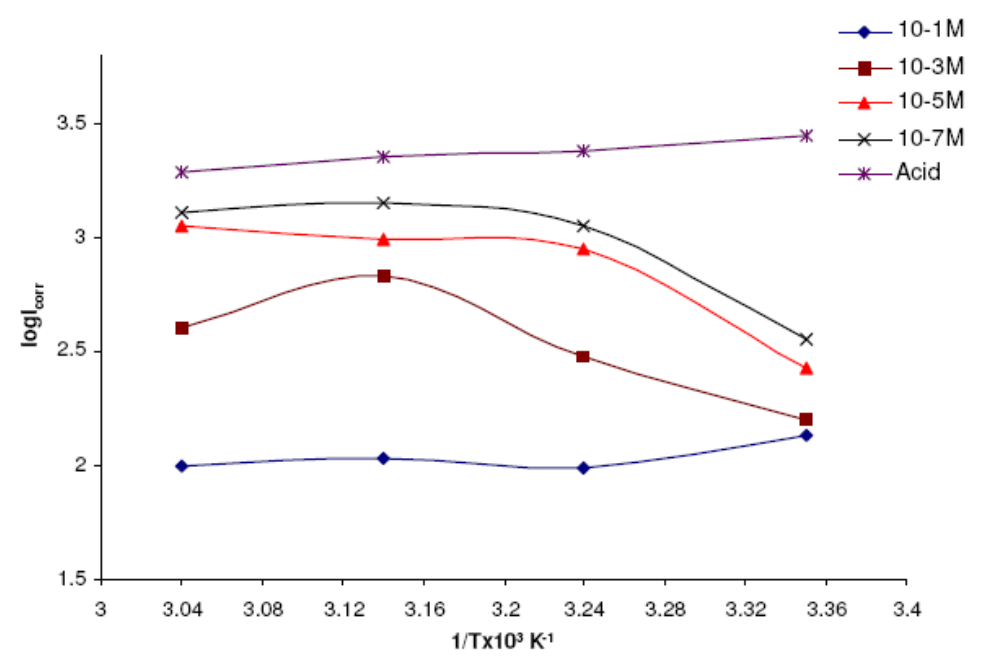

Figure 8. Variation of corrosion current vs. reciprocal of temperature at different concentrations of TBAI.

Table 3. Fourier transform infrared bands of pure and adsorbed tetra-N-butylammonium iodide (TBAI) inhibitor.

\begin{tabular}{ccc}
\hline TBAI & TBAI $^{\text {ads }}$ & Peak \\
& & \\
\hline 2987.1 & 2987.4 & C-H \\
1472.5 & 1472.7 & C-C \\
990.4 & - & C-O \\
1257.0 & - & N-C \\
1655.4 & 1620.0 & N-H \\
\hline
\end{tabular}

\section{Scanning electron microscopic study}

To study the surface morphology of mild steel coupons, SEM technique has been used. Fig. 9, 10, 11 and 12 show the surface morphology of plain mild steel, in 1 $\mathrm{N} \mathrm{H}_{2} \mathrm{SO}_{4}$ and corroded surfaces after dipped in TBAI inhibitor at $10^{-7} \mathrm{M}$ and $10^{-1}$ M. The micrographs obtained from different concentrations show that the surfaces are inhibited due to the formation of insoluble stable film of mild steel surface. It proves that the additive acts as good inhibitor at higher concentration $10^{-1} \mathrm{M}$.

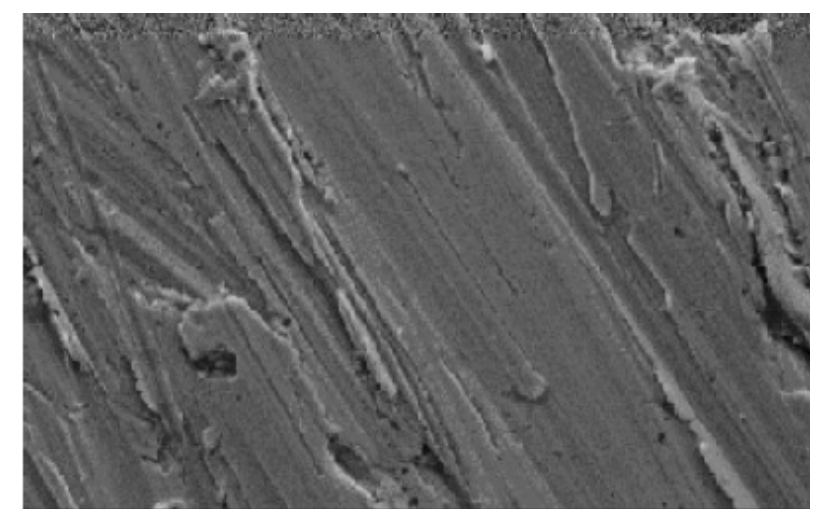

Figure 9. Scanning electron micrograph of plain mild steel at 2000 magnification. 


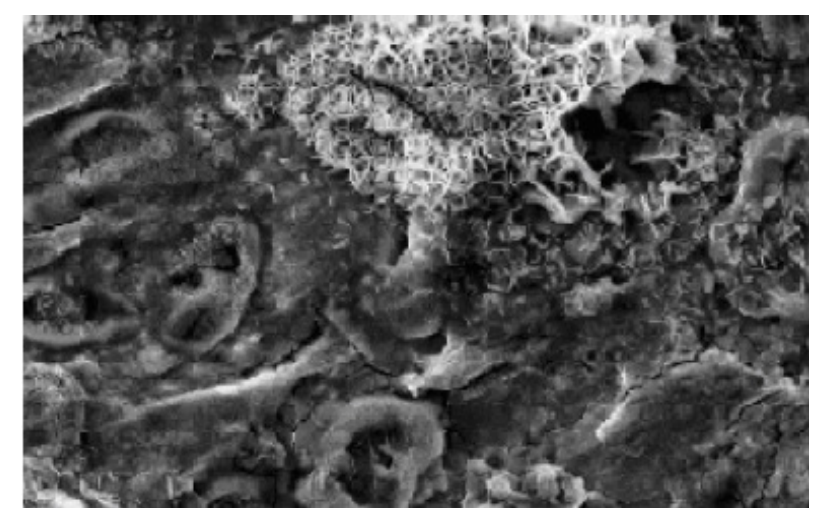

Figure 10. Scanning electron micrograph of mild steel in $1 \mathrm{~N} \mathrm{H}_{2} \mathrm{SO}_{4}$ at 2000 magnification.

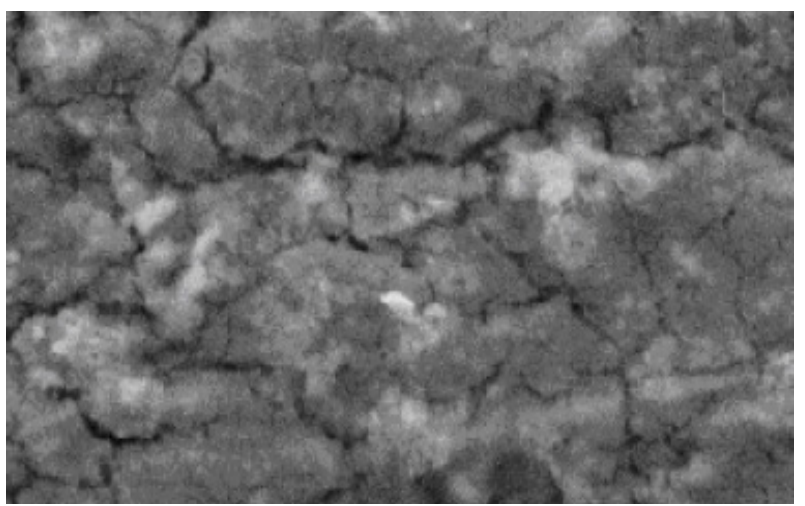

Figure 11. Scanning electron micrograph of mild steel in the presence of $10^{-7} \mathrm{M}$ TBAI in $1 \mathrm{~N} \mathrm{H}_{2} \mathrm{SO}_{4}$ at 2000 magnification.

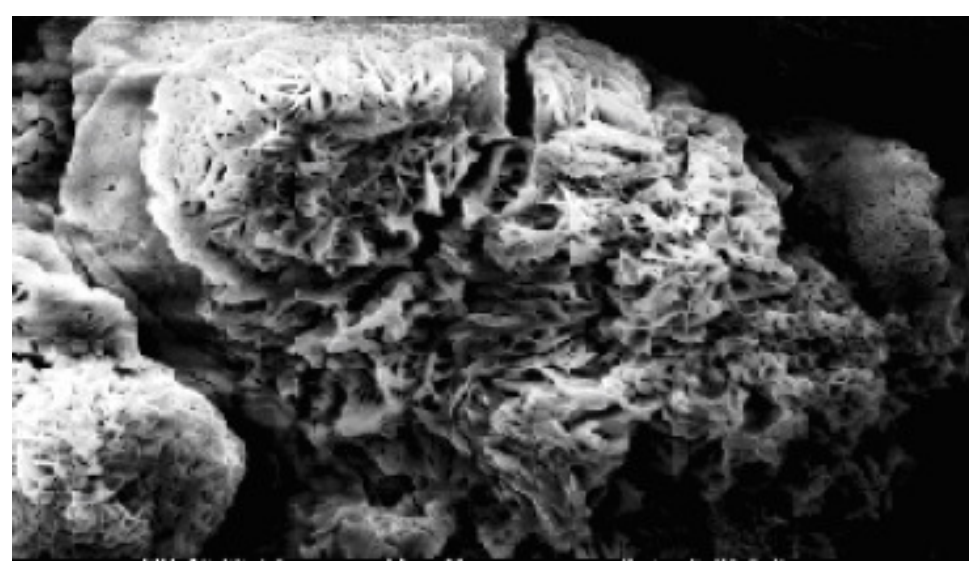

Figure 12. Scanning electron micrograph of mild steel in the presence of $10^{-1} \mathrm{M}$ TBAI in $1 \mathrm{~N} \mathrm{H}_{2} \mathrm{SO}_{4}$ at 2000 magnification.

\section{References}

1. S.M. Abdel Wahaab and G.K. Gomma, J. Chem. Tech. Biotechnol. 36 (1986) 185.

2. G.K. Gomma, Bull. Electrohem. 4 (1988) 941.

3. G.K. Gomma, R.M. Issa, H.Y. El-Baradie and E. Shokry, Bull. Electrochem. 8 (1992).

4. G.K. Gomma and Y.L. Aly, Bull. Electrochem. 9 (1993) 53. 
5. G.K. Gomma, J. Indian Chem. Soc. 70 (1993) 130.

6. G.K. Gomma and M.H. Wahdaan, Material Chem. Phys. 39 (1994) 142.

7. M.H. Wahdaan and G.K. Gomma, Material Chem. Phys. 47 (1997) 176.

8. G.K. Gomma, Material Chem. Phys. 56 (1998) 27.

9. G.K. Gomma, Material Chem. Phys. 55 (1998) 235.

10. G.K. Gomma, Material Chem. Phys. 55 (1998) 131.

11. G. Trabanelli and V. Carorrite, Advances in Corrosion Science and Technology (M.G. Fontana and R.W. Stachle, Eds.) Vol. I. Plenum, N.Y. $1970,147$.

12. I.L. Rozenfeld, Corrosion Inhibitors (NewYork, NY: McGraw-Hill) (1981) 327.

13. G. Gradner in "Corrosion Inhibitor", Ed. C.C. Nathan (Houston, TX: NACE) (1973) 156. 